\title{
Mobilizing the Sense of "Fat": A Phenomenological Materialist Approach
}

\author{
Jenny Slatman ${ }^{1}$ (D)
}

Accepted: 24 June 2021 / Published online: 13 July 2021

(C) The Author(s) 2021

\begin{abstract}
This paper aims to mobilize the way we think and write about fat bodies while drawing on Jean-Luc Nancy's philosophy of the body. I introduce Nancy's approach to the body as an addition to contemporary new materialism. His philosophy, so I argue, offers a form of materialism that allows for a phenomenological exploration of the body. As such, it can help us to understand the lived experiences of fat embodiment. Additionally, Nancy's idea of the body in terms of a "corpus"- a collection of pieces without a unity-together with his idea of corpus-writing-fragmentary writing, without head and tail—can help us to mobilize fixed meanings of fat. To apply Nancy's conceptual frame to a concrete manifestation of fat embodiment, I provide a reading of Roxane Gay's memoir Hunger (2017). In my analysis, I identify how the materiality of fat engenders the meaning of embodiment, and how it shapes how a fat body can and cannot be a body. Moreover, I propose that Gay's writing style-hesitating and circling - involves an example of corpus-writing. The corpus of corpulence that Gay has created gives voice to the precariousness of a fat body's materialization.
\end{abstract}

Keywords Fat embodiment · Materialism · Phenomenology · Jean-Luc Nancy · Roxane Gay

\section{Introduction}

In her memoir Hunger (2017), Roxane Gay, a feminist writer and academic, claims that people are often very surprised to see that a fat person could be so successful. Most people, she writes, think very little of fat people, assuming that they are neither smart nor capable (2017: 241). This is a telling example of what Graham has termed "lipoliteracy," i.e., reading fat for what we believe it tells us about a person

Jenny Slatman

j.slatman@tilburguniversity.edu

1 Department of Culture Studies, Tilburg School for Humanities and Digital Sciences, Tilburg University, PO Box 90153, 5000 LE Tilburg, The Netherlands 
(2005: 178). In today's Western societies, fat is often only seen as a signifier for the following pejorative traits: being unhealthy, stupid, gluttonous, lazy, clumsy, and incompetent. Fat, indeed, has a very negative meaning. This paper aims to mobilize the way we think and write about fat bodies while interpreting Gay's memoir through the conceptual lens of Jean-Luc Nancy's philosophy of the body. Nancy's philosophy involves an ontology of the body, which pertains to the body as such, and does not include analyses of different types of embodiment, such as fat embodiment. Yet, I believe that some of his ideas on the body and writing can be helpful to understand fat from an alternative perspective.

Needless to say, lipoliteracy almost always goes together with overt and unabashed discrimination and stigmatization of fat people. In contemporary discussions about the negative meaning of fat, spearheaded by critical fat studies, emphasis on politics of inclusion is therefore seminal. Fat acceptance and body positivity movements strive to show that fat embodiment, instead of being "deviant," involves a type of embodiment that fits within the range of human body diversity. Critical fat studies thus counter the dominant medical view on fat according to which fat bodies are considered as deviating from "normal" body weight. From a medical and public health perspective, fat is seen as a health problem localized in an individual body, which subsequently can be solved by adjusting that individual body to the norm (through dieting, more exercise, or surgery). Fat scholars criticize this view for several reasons; not in the least because it is not at all self-evident that a fat body can be turned into a thin body (Gaesser 2009; Harding and Kirby 2009; Kolata 2007). Because of this criticism, they tend to take discussions about fat out of the medical domain and turn them into a political discussion (e.g., LeBesco 2004).

Precisely because critical fat studies aim at achieving political and social goals such as countering discrimination and stigma, and adapting public spaces to larger bodies, it is fruitful to look at fat from a disability studies perspective (Mollow 2015). As is well-known, disability studies distinguish between the medical and the social model, whereas the former entails the view that impairments imply a physical or mental defect in an individual, the latter holds that it is the society that produces disability (Oliver 1996). Contemporary voices within disability studies, however, argue that we miss the full extent of the phenomenon of disability if we only embrace the social model (Shakespeare 2013), or if we do not account for the material relations between body and environment (Garland-Thomson 2011). This shift away from the social model towards a materialist-oriented approach could also be productive for understanding fat. Mollow (2015), for instance, cautions that fat should not only be approached from a social model angle because that would result in a negation of fat's physical side. For standing up for your rights, such as access to appropriate care, you need to also recognize the physical side of fat, Mollow (2015: 207) claims. Fat is political but it is also physical or material. Indeed, to mobilize the sense of fat, we should address it as a political-material issue.

In addition to this, I would like to add that fat's meaning cannot be cut off individuals' lived experiences. By this, I mean that we must not forget, even if we assume that fat is not simply an individual physical problem, that individuals with fat bodies have their own lived experiences of being fat within a particular socio-political and material constellation (e.g., Murray 2008, especially part III). Individuals with fat 
bodies, so I suggest, should have the space to voice how they experience their being fat in a fat-phobic society, rather than having either the medical discourse or the fat acceptance discourse dictate to them what they should think of their bodies. In this paper, I will therefore analyze the meaning of fat through a phenomenological materialist approach. To explore the lived experience of fat, I will rely on a singular voice: Roxane Gay's memoir Hunger (2017). Her writing style, so I claim, can also be understood as an example of thwarting lipoliteracy.

\section{Phenomenological Materialism}

In contemporary sociology of health and critical geography, various studies on fat employ a materialist view to complement social-constructivist approaches, and to point out that fat bodies and non-fat bodies differ materially, and that difference in matter actively contributes to the difference in meaning (Colls 2007; Forth 2013; Fox et al. 2018; Norman and Moola 2019; Rice 2015; Warin 2015). Within this view, matter is no longer understood as a passive substance that receives its meaning by a certain discursive practice but as something that actively contributes to its own meaning. In this paper, I will contribute to the materialist approach to analyzing fat embodiment. However, whereas the majority of these new materialist studies are inspired by Deleuzian thinking (through, for instance, Barad 2003, Grosz 1994, Braidotti 2002)—which tends to position itself as anti-phenomenological since it searches for agency, intensity and affectivity beyond or beneath the scope of intentional subjectivity - I would like to propose here, perhaps a bit recalcitrant, a phenomenologically oriented form of materialism. For this, I will draw on the work of the contemporary French philosopher Jean-Luc Nancy. To my knowledge, Nancy's philosophy has, except for some brief comments (James 2006: 114f.; Morin 2016, footnote 2), not yet been included in current debates about new materialism, and has never been used to analyze fatness.

It might be odd to present Nancy's work as phenomenology since he does not self-identify as a phenomenologist. Moreover, Nancy has formulated some explicit criticism on Husserl's and Merleau-Ponty's idea of the lived body (Nancy 2008: 128) and he discards Husserl's idea of the phenomenological reduction. Yet I believe that his reflections on the body can be considered as phenomenological. According to phenomenology, meaning or sense emerges in the interaction between self, other and world. To trace this constitution of sense (Sinngebung), Husserl, the founder of phenomenology, proposed to first bracket realist beliefs, and to focus on the subject's intentionality. As said, Nancy does not adopt this idea of the phenomenological reduction, but I believe that he does share with phenomenology the idea that sense (which is a central theme in his work) emerges in the interaction between self, other, and world, although he redefines this interaction. Unlike mainstream phenomenology, he assumes that sense is not borne by an individual signifying subject. The starting point for his ontology of the body is "being with" (être-avec). According to him, being in the world means a physical existence amid a multitude of other bodies: human bodies, other living bodies, and non-living bodies (Nancy 1996: 84). What characterizes all (material) bodies is that they occupy a certain place, that they are 
extended in space and that when they take their place, they always touch other bodies. Or rather, we should say that bodies only emerge when they touch or are touched by something or someone else. It is through touch that a body appears as distinct from other bodies. The "being with" of bodies implies that bodies are parts that exist outside each other: partes extra partes. By assuming "being with" and partes extra partes, Nancy indicates that the emergence of sense cannot be traced back to individual intentional subjects. Sense happens because bodies touch each other all the time. We might say that the interaction between self, other, and world is redefined by Nancy in terms of touch. For him, the appearance of sense takes place within relational constellations. So, what Nancy shares with the phenomenologists is that he does not suppose that sense is simply given, but holds that it occurs continually, and that it is this ongoing emergence that we need to explore.

Because Nancy understands touch as that which gives meaning to individual and distinct bodies, that which lets bodies take up a place, it becomes clear that the outside or the "exteriority" of bodies is crucial. In his critique of Husserl and MerleauPonty where he refers to the example of the two touching hands, that is so crucial in their respective conceptions of the lived body, he argues that these two philosophers have not properly understood the nature of touch because according to them, selftouching results in a return to interiority (2008: 126). Without going into further detail here as to whether this characterization of Husserl's, and particularly MerleauPonty's philosophy is correct-this discussion is beyond the scope of this paper-I follow Nancy here in his line of thought that touching and being touched always happens on the outside, and can only take place because the body is "outside," because it is exposed. Even though Nancy criticizes phenomenology for considering the first-person experience as internal, and as leading for sense-making, he does pay attention to first-person perspective experiences. This dimension of his work is most evident in his essay "On the soul" (Nancy 2008: 122-135). This essay emphasizes the role of one's body's experiences, and this fits well in a broader and nonphilosophical idea of phenomenology (such as used in empirical phenomenological research) in which the analysis of lived experience is put central, without worrying about the desirability or possibility of a phenomenological reduction (Zahavi 2020).

In "On the Soul," Nancy underlines that self-experience is a necessary condition for being a body. A body is only a body if it can sense itself. When the body does not sense itself, that is, when the body is dead, insentient, or numb, but also in cases of total health, it is no longer a body. A body that does not feel itself is "mass" (2008: 129). When reduced to mass, the body has become untouchable and indifferent and thus stops being body. This is why Jakešová (2020) describes mass as "unbody". The body is material but not in the sense of mass. "The matter of the body is sensing matter" (2008: 127). So self-experience is part of the definition of being a body. We must not place this self-sensing "in" the bodily subject, but in the extra of the partes extra partes, or as Nancy often says, it takes place on the limit. Sensing matter might imply an experience of self, but only so because it presupposes an outside perspective.

In Nancy's work, "mass" not only refers to insensate matter but also to the opposite of crowd or plurality: "There's always a crowd (une foule) of bodies, there's never a mass of bodies. Where there's a mass of bodies, there's no more body, and 
where there's a mass of bodies, there's a mass grave" (2008: 124). Bodies piled up in a mass also are "un-bodies," bodies that are denied their being-body. Even though Nancy uses the trope of the mass grave here, he directly adds that there are many kinds of living bodies (tortured, violated, wounded, humiliated) whose being-body can be denied (2008: 122). Thus, there may be bodies that can sense themselves, which nonetheless are reduced to mass or "un-body" because they are no longer part of the plurality of the crowd. When bodies are reduced to mass, in the sense of the opposite of crowd or plurality, it means that they cannot take place. As soon as it is assumed that bodies can be collected in a mass, that they can be "abandoned to the stochastic confusion of the same places" (Nancy 2008: 139), then they lose their own place and stop being a body, in the sense of being singular plural (Nancy 1996). The starting point for my materialist interpretation is that when fat bodies are humiliated and excluded, it means not only that these bodies do not conform to certain social norms, but primarily that these bodies cannot take place, that they are reduced to mass, that they do not participate in "being-with". In this paper, I want to investigate how we can interpret this exclusion of fat bodies in a materialistic sense, without falling back on a (static) biological or physical idea of fat. Instead, I will look at how lived experiences of fat arise in the material relations between material bodies (living or inanimate), between bodies and (material) environment.

\section{The Lived Experience of Fat}

As a way to explore the lived experience of fat embodiment, one might choose to conduct interviews with fat people or to analyze the experiences of fat people on social media. Several phenomenological studies of fat (and weight-loss) have been carried out based on such an empirical approach, providing an understanding of how fat people experience their fat body in a fatphobic society (e.g., Cooper et al. 2018; Groven et al. 2013; Natvik et al. 2019; Sneed 2012; Vartanian et al. 2014; WindramGeddes 2013). I have chosen, however, to use a published book as a source for my analysis of fat, because I would like to highlight the role of writing. It is through a typical style of writing, so I suggest, that the sense of fat can be mobilized beyond lipoliterate readings.

Roxanne Gay (born in 1974) is a professional writer who expresses the plural experiences of fat embodiment very vividly. In Hunger (2017), she narrates what it is like to live with a fat body as a black woman raised in a middle-class HaitianAmerican family. In quantitative terms, she describes her body as "super morbidly obese" (i.e., a BMI > 50) and tall $(1.90 \mathrm{~m})$. The term she often uses to emphasize that her body fits so badly in this world is "unruly body". Her memoir involves the lived experience of her "unruly body," or in Nancian terms, a body prone to losing its "being body". Hunger is a "memoir of (my) body" writes Gay. It concerns a writing about her own body (a memoir of my body), but simultaneously about beingbody in general (a memoir of body). In line with Nancy's thought, we could say that it involves a writing that does not simply result in a unified representation or identification of that body. As I will explain in more detail below, Nancy argues that a body never forms a clear unity: a body exists because it constantly differs (from itself, 
from others). A body exists as a collection without internal unity, a "corpus corporum" (Nancy 2008: 155). Moreover, to do justice to this corpus, we should develop a body vocabulary in the form of such a corpus. Corpus writing involves writing in fragments and "the fragmentation of writing" which, according to Nancy, is necessary to "respond to the ongoing protest of bodies in-against—writing (dans-contre-l'écriture)" (2008: 21). It is through this fragmentary writing and through what he calls "excription" that writing can do justice to the non-unified character as well as the singularity of each body.

Similarly, Gay's book exudes the complexity of writing about one's body without pinning it down to a particular meaning. She writes: "I hesitate to write about fat bodies and my fat body especially" (2017: 139), and she also describes her own way of writing as a writing "around what happened to me" (2017: 33). To what her story circles back, again and again, is a traumatic event in her childhood. She had been sexually abused when she was only twelve years old and this event has marked a crucial shift in the way she experienced her own body and the way she could endow meaning to it. Although my analysis in this paper relies on the experience of a single fat person and does not have the intention to generalize this experience, it is nevertheless important to note here that Gay's story does not stand alone. It is well known that women who have experienced sexual violence during their childhood are at high risk of becoming fat (e.g., Noll et al. 2007). Precisely because the sexual abuse has been such a traumatic event, it is not strange that Gay indicates that there is no direct way to write about it. You can only write "around" it. In the same way, she writes "around" her childhood trauma, while approaching it constantly from another angle, she expresses her experiences of being fat in a fatphobic world in a pluralistic way. Gay's writing, then, may also be considered an example of "corpus-writing": a form of writing - hesitating, circling, and iterating the same but different every time in short chapters - that does not reduce a body to a fixed meaning. Nancy's differential idea of bodies, together with his ideas about writing that resists rigidifying the meaning of signifiers can help us to mobilize the sense of fat. Analyzing Gay's memoir through the theoretical lens of Nancy, I will explain how her writing can do justice to a palette of experiences of fat embodiment without relying on a definite identification with (being) fat.

\section{How the Matter of Fat Matters}

New materialist studies of fat have examined how matter plays a role in what Butler (1993) has called the "materialization" of bodies, i.e., the process in which bodies can become intelligible bodies. For instance, Colls explains that fat, as a substance at once independent and localized under the skin, produces a shift in body boundaries together with the production of a body that was not previously knowable (2007: 358f.). Whereas Colls refers to the agency implied in the substance of fat, Warin points at the dynamic agential dimension of matter while drawing on epigenetics in terms of a "relational biology" (2015: 62). In my materialist reading of fat, I will focus on weight and space, adhering to Nancy's conception of bodily matter as sensing matter. Here I will analyze how fat's weight 
and space - such as narrated by Roxane Gay-contribute to the production of a body that she calls "unruly".

According to Nancy, a material body is defined by weight, but weight is not just a quality of a body, as, for example, color and shape are body qualities. Weight is what a body is. He writes:

A body doesn't have a weight: even in medicine, it is a weight. It weighs on, it presses against other bodies, right up against other bodies. Between it and itself, it's still weighing, counterweight, buttressing. (2008: 93)

A body is a body because it weighs; it is only because of its being weight that a body can touch another body and can be touched by another body. Weight thus defines the body's material existence. A weightless body is a contradiction in terms. In another text, Nancy even claims that, instead of the Kantian a priori forms space and time, weight forms the condition of the possibility for perception: "The weight of a localized body is the true purely sensible a priori condition of the activity of reason: a transcendental aesthetics of gravity (pésanteur)" (Nancy 1997: 77). Without being pressed against the earth, without feeling the weight of our own physical existence, we would not be able to perceive. As such, the body's materiality, which is weight, is not passive, but something active, agential: it presses, it weighs, and it pushes and pulls.

Let us now explore how weight enacts within a heavy and large body, and between this body and its material environment, based upon Gay's narration:

When I move around, I feel every extra pound I am carrying. I have no stamina. When I walk for long periods of time, my thighs and calves ache. My feet ache. My lower back aches. More often than not, I am in some kind of physical pain. Every morning, I am so stiff I contemplate just spending the duration of the day in bed. I have a pinched nerve, and so if I stand for too long, my right leg goes numb and then I sort of lurch about until the feeling returns. (Gay 2017: 16)

Fat's weight disallows her to move lightly and it presses against other parts of her body, causing pain, discomfort, and stiffness. To be able to carry so much weight, the body has to put in extra effort, which will warm it up. Fat's weight thus results in abundant sweating:

When it is hot, I sweat profusely, mostly from my head, and then I feel selfconscious and find myself constantly wiping the sweat from my face. Rivulets of sweat spring forth between my breasts and pool at the base of my spine. My shirt gets damp and sweat stains begin seeping through the fabric. (Gay 2017: 16)

In general, Gay says that the extra weight of her fat body makes her life heavier. Everything takes more effort for her. An important motive for losing weight is therefore 
to lighten her physical burden. As she writes: "There is always a moment when I am losing weight when I feel better in my body. I breathe easier. I move better. I feel myself getting smaller and stronger" (2017: 142f.). She also writes that she never liked sports much, except for swimming: "I loved the water, the freedom of moving through it, feeling weightless" (2017: 72). Through the material relation between her body and the water, her body is being granted to be a body in the Nancian sense.

From the description of Gay, we learn that an excess of body weight can hamper daily life. If we apply Nancy's ideas here, we could say that if weight is the condition of possibility for bodies touching one another, and thus for bodies to sense themselves, an excess of weight, such as described by Gay, might produce an excess of self-sensing which hinders to feel what is outside of one's own body. In other words, the sensing of one's heavy matter reinforces the feeling of oneself, of one's own body. The heaviness of fat presses into one's own body and creates an inflated feeling of one's own body. When the pressure of that weight can be taken away, as in the experience of swimming, then there will be room to feel what is outside the body, in this case, the water. Nancy would not call the feeling of floating in water "weightless" because water also has a weight (or, is weight), through which the matter of the water and the human body can touch each other. The feeling of "weightlessness" in water, therefore, is a clear experience of contact or touch between one material body and another. The excess of body weight, however, in the case of Gay, results in a body being less able to be touched. The weight of fat can therefore contribute to a body becoming more and more isolated and detached from the crowd of bodies.

Next to weight, the matter of body fat is directly related to size and thus to being spatially extended. Body fat materializes the way fat bodies occupy space. As Gay points out, most people are not at all concerned with the way they occupy space. This, however, does not apply to herself:

I am hyperconscious of how I take up space. As a woman, as a fat woman, I am not supposed to take up space. And yet, as a feminist, I am encouraged to believe I can take up space. (2017: 156)

The feeling that she is not supposed to take up any space translates into specific behavior: folding herself up as much as possible (against the window of the plane) so as not to get in the way of fellow passengers; walking at the edge of the sidewalk; walking as fast as possible so that she bothers no one. People with smaller bodies can take up much more space scot-free, without having to think about it, than people with fat bodies (p. 157). Fat thus materializes an ambiguous experience of spacing: a fat body needs more physical space than non-fat bodies, yet it is allowed less space. Gay expresses this as follows:

I take up space. I intimidate. I do not want to take up space. I want to go unnoticed. I want to hide. I want to disappear until I gain control of my body. (2017: 11) 
Fat not only requires physical space, but it also forces a different way of dealing with the space that most people take for granted. Chairs designed for average bodies are not suitable for fat bodies. Material "misfits" (Garland-Thomson 2011)-i.e., the failure of relations between material bodies (living or inanimate)-are commonplace for fat people. Gay writes that she always tries to figure out which chairs are in a restaurant or lecture hall before she goes there. There is a constant feeling that her body does not fit in the space. "Physical spaces punish me for my unruly body" (2017: 184). The failure of the relation between the fat body and its material environment materializes discomfort in the sense that it evokes pain, welts, and bruises; when aircraft seats or public toilets are too small; when seat belts are too tight. It materializes discomfort because it leads to shortness of breath, prohibiting walking and talking at the same time (2017: 187). It materializes humiliation when you are unable to climb a stage without stairs in front of a room full of people, and when you subsequently have to squat for two hours because you are afraid that the unsteady chair will collapse under your weight (2017: 242). For Gay, these instances of bottomless shame indicate that there is no place for her body in this world: "the world cannot accommodate a body like mine" (2017: 243). A world set up only for average and slim bodies creates a material misfit with fat bodies. It is not surprising that the disembodied space of the internet is one of the few spaces in which Gay feels comfortable. In online communities, material relations are virtually non-existent.

These descriptions of Gay show how the matter of body fat, in the capacity of size, can lead to a situation where no place can be taken. The space given to the fat body is not space for the body, but for mass (in the sense as the opposite of crowd or plurality). What we see here, and we saw this above with the phenomenon of weight, is the active role that the matter of fat plays in the exclusion of fat bodies. The matter of fat is thus implicated in the process of materialization. To be more precise, these examples of weight and space make clear, how the matter of fat can contribute to the negation of being-body of fat bodies. However, it would be a wrong conclusion to say that the more fat a person has, (and the heavier they are), the less their body can be a body. My phenomenological-materialist reading is not about correlating the amount of body fat to the degree to which a body is excluded. It rather shows fat's active role in the discrepancy of material relations, and at the same time it describes the lived experience of such a discrepancy, or in Garland Thomson's terms, of such a "misfit". Indeed, Gay's experience of not being accommodated in this world is not simply caused by her large body. It is rather the effect of a poorly fitting relation between her body and her material environment, including social norms which are substantiated in the way public space is laid out.

It would also be wrong to believe that Gay's memoir is solely about a body that tends to be an "un-body". She also narrates experiences of fat that contribute to being a body. Fat can materialize a new, alternative body. In her materialist study on fat, Colls has explained how the materiality of fat may result in the emergence of new body regions, such as "low-full-folds-that are-sides" (2007: 359), and hence in the change of bodily geography. When Gay alludes to the idea that fat has created something new, she does not talk about new zones, but about an entirely new body: "one that shamed me but one that made me feel safe. I needed to feel like a fortress, impermeable. I did not want anything or anyone to touch me" (2017: 14). Turning 
her body into an impermeable fortress, fat provides a sense of comfort and security; it ensures that no one can assault or rape her again. Paradoxically, fat also makes you socially invisible. Gay experienced that when, as a student, her parents put her on a diet after which she lost more than forty pounds. She was terrified because she felt that she was losing her "newfound invisibility" (2017: 59). This fear, panic even, to lose her protective bodily layer, returns after every attempt to lose weight. "I start to worry about my body becoming more vulnerable as it grows smaller. I start to imagine all the ways I could be hurt" (2017: 143).

In the case of Roxane Gay, the creation of a new form of embodiment can be seen as a kind of healing mechanism for her violated, abused body. As aforementioned, Nancy describes bodies worthy of the term body as singular plural beings that touch one another. A body that can be part of a crowd is distinct. Nancy underlines that touching happens at the outside from bodies; it happens at the limit between one body and another. To secure the distinct, singular nature of a particular body, this body's impenetrability should be respected. When touching at the outside transforms into a violation of the body's surface-literally or figuratively-this will destroy the body: "A body's material. It's dense. It's impenetrable. Penetrate it, and you break it, puncture it, tear it" (Nancy 2008: 150). When Nancy talks about penetration, he is not necessarily talking about the penetration of sexual intercourse. Consensual sexual intercourse involves, according to Nancy, two bodies touching one another at the outside while respecting one another's distinct body. Penetration in the Nancian sense, by contrast, implies the destruction of that outside. This is the case with rape and violence, but also with all other ways in which bodies are regarded as mass and not as singular bodies within a crowd. Gay's biography of her body is not just a story about her fat body. It is a story that circles around the destruction of her body in her teens. In her story, the accumulation of fat serves the creation of a new kind of body. Childhood abuse may lead to fatness, as is the case for Gay and many other women, but sadly enough, fatness is not always an effective protection since it easily incites new forms of abuse. Indeed, many women of size have to deal with cruel anti-fat violence (Royce 2009).

\section{Against Incarnation}

Gay's story is not uplifting, it is not a "story of triumph," not a "success story," but as she writes at the start of her book "a true story" (2017: 2); a story that needs to be told. Fat people get virtually no opportunity to tell the story of their bodies because others already have a story to tell about fat bodies:

When you're overweight, your body becomes a matter of public record in many respects. Your body is constantly and prominently on display. People project assumed narratives onto your body and are not at all interested in the truth of your body, whatever that truth might be. (2017: 110)

Gay thus challenges the superficial reading of bodily signifiers. Nancy writes "the body is neither a 'signifier' nor a 'signified' [...]. The body is the architectonics of 
sense" (2008: 25 , italics in original). The claim that the body is neither a signifier nor a signified goes against the deep-rooted tendency to perceive a material thing-a sign or a body - as something that refers to something else. When bodies are understood as signs, they become entangled in a process of signification. Instead of singular bodies, they become specific signifiers referring to a specific, rigidified meaning:

bodies of misery, bodies of famine, beaten bodies, prostituted bodies, mutilated bodies, infected bodies, swollen bodies, over-nourished bodies (corps bouffis), too body-built, too erectile, too orgasmic. (Nancy 2008: 79)

As we can see in this quote, the process of the signification of bodies is always about normative interpretations, bodies that are too much of this or too little of that. It is about identifying bodies that do not conform to the norm, bodies that deviate. Nancy suggests that the interpretation of bodies is often guided by hate, stating: "It is no wonder the body inspires so much hatred" (2008: 9). As long as bodies are conceived of as material signifiers, they easily invite hateful readings resulting in exclusionary and stigmatizing practices.

Nancy's work can be helpful because he indicates that hate for bodies is a consequence of the fact that we interpret bodies as signifiers. Bodies are wronged because they are held captive in a process of signification. Nancy proposes that we have to look beyond (or beneath) this process of signification claiming that if we want to do justice to bodies - to the ontology of bodies—we have to talk about their "sense". In contrast to "signification," the French term "sens" has multiple meanings: it refers to (1) sensibility, the senses, the sensuous, instinct, judgment (e.g., bon sens), opinion, (e.g., à mon sens); (2) signification, meaning, value (avoir un sens); (3) direction, position. This latter meaning also includes the indefinite process of "being directed to something". For Nancy, sense is, therefore, about the way bodies are positioned in and directed to the world. Sense is about bodies that take place and that occupy a certain space. This fundamental process of the spacing of bodies has been overshadowed, however, by the ubiquitous practice of signification. Nancy, therefore, offers a deconstruction of signification, which runs parallel with what he calls his "deconstruction of Christianity". The practice of signification is based on the principle of incarnation - a principle, which, according to Nancy, underlies Christianity, and Western culture in general.

In Christianity, incarnation stands for the process according to which the immaterial God becomes material and thus embodied through the Son. And vice versa, the human body of the Son refers to the immaterial God. We find this principle everywhere when it comes to giving meaning. Indeed, if we take a sign as a signifier, we assume that the present, material sign refers to something that is not materially present, the ideal meaning of something. This is something we do daily when we interpret the things around us.

However, when it comes to the interpretation of bodies, Nancy argues, such a signification process does not do justice to what it means to be a singular body amidst other bodies. As described above, a body that appears as a singular body, because it is touched and thus separated from other bodies, is a body that exists as an exterior, and whose exterior remains intact. When a body is not only touched, but is 
penetrated, it loses its outside and breaks down, and ceases to be a singular body. An assumption in Western thought, according to Nancy, is that the body can also be penetrated by something non-material. Such penetration of the material by the non-material is what exactly underlies the principle of incarnation. If, however, we start from the fact that bodies exist as partes extra partes, as parts outside each other that do not penetrate one another, then the idea of incarnation is impossible, writes Nancy:

[We] can in no way think the body in terms of incarnation. I am speaking not only of the Christian dogma of incarnation, where that which is without place, without exteriority, without form, without matter (God) comes into flesh, but of the incarnation that is the model (itself Christian, in effect) of all our thought on the subject. This idea of incarnation is impossible: what does it mean that something without place would come to occupy a place? (2008: 132)

When we understand the appearance of a body as that which appears through an ongoing (infinite) spacious process of occupying a certain place, we should not search for its meaning in a process of incarnation or significance. The sense of bodies is not their meaning or signification but rather their creation, or their own "spacing" in the middle of other bodies. The sense of a body is that it can occupy a place, take up space through its being extended and through touching and being touched by other bodies. There is no other meaning to be sought beyond this permanent process of bodies touching one another and taking a specific place. "Bodies demand, yet again, their creation. Not an incarnation inflating the spiritual life of the sign, but a birthing and a sharing of bodies" (Nancy 2008: 83).

This criticism of the principle of incarnation presents us with a problem, for if we do not conceive of the body as a signifier or sign, how can we say anything about bodies? How can justice be done to the absolute singular existence of bodies in writing? Nancy says: "Let there be writing, not about the body, but the body itself" (2008: 9). Elsewhere he says that we should not make a discourse about the body, referring to Plato's idea that a discourse can be compared to the body of a large animal in the sense that it should have a head and a tail and a middle, and that these parts should be well organized among themselves (2008: 122). Plato's idea of how we should write a text still largely corresponds to how we instruct our students today to write a coherent text. Nancy, on the other hand, claims that this form of coherent writing does not do justice to the existence of bodies. A body is not a coherent whole. It is an ongoing changing collection-corpus-of (replaceable) parts and functions. To do justice to ever-changing collections, we must also write in the form of a corpus.

\section{Corpus Writing: Testifying to Non-Unified Bodies}

To get an impression of what corpus writing would entail, it is instructive to look first at Nancy's own style of writing, which is rather aphoristic and sometimes even fragmentary. Unlike philosophers such as Heidegger and Derrida, he rarely 
invents neologism. He rather continues using common concepts - such as body, soul, matter - but continuously transfers these through his circular style of writing (Morin 2012: 3-5) An often-used trope in his circular writing involves the listing of words, for instance:

A body is an image offered to other bodies, a whole corpus of images stretched from body to body, local colors and shadows, fragments, grains, areolas, lunules, nails, hairs, tendons, skulls, ribs, pelvises, bellies, meatuses, foams, tears, teeth, droolings, slits, blocks, tongues, sweat, liquors, veins, pains, and joys, and me, and you. (2008: 121)

As you can see, enumerations like these include a mix of anatomical or physical parts and experiences, and of nouns and verbs. Morin therefore says that these enumerations often contain "category mistakes" confusing "the body I experience in the first person with the body conceived from the third-person perspective" (2016: 19). Corpus writing is thus about bringing together all kinds of dimensions of a body that matters at a given moment.

When we look at Roxanne Gay's way of writing, we could say that her body memoir also includes circular writing, even though she does not use the trope of enumeration. Her text consists of eighty-eight short chapters, each of which is never longer than a few pages. Some are even much shorter. For example, chapter one consists of two sentences and chapter five of six short sentences. All chapters form completed entries, but sometimes it is as if every chapter involves a new beginning of the story. Instead of depicting a sequence of events, individual chapters each address a particular aspect of life with a fat body. Sometimes the statements she makes seem to contradict one another. For example, she says "I hate myself" to say a paragraph later "But I also like myself" (2017: 135). Throughout the book, she constantly indicates what the physical limitations of her fat body are, only to say later in the book: "This body is resilient. It can endure all kinds of things. My body offers me the power of presence. My body is powerful" (2017: 272). These contrasting statements indicate that Gay does not conceive of her body in one specific way, that she is not unequivocal about what it means to have a fat body. They also give expression to embodied identity in terms of an ongoing plural process instead of having a fixed outcome.

In his essay "Fifty-eight indices on the body" (2008: 150-160), Nancy provides a corpus of fifty-eight indices, each of them saying something about the body. These indices together do not form a stable entity, especially because some indices conflict with one another. For instance, Nancy starts indices one and two claiming "A body's material," but starts index five while stating "A body is immaterial" and then says in index eight "The soul is material" (2008: 150f.). We could say that this enumeration of contradictory clues mobilizes rigidified meanings and convictions about what a body is. At the same time, it also forms a way of writing that can do justice to the way bodies are. Nancy is very explicit about the use of the index as a rhetorical device: 
Why indices? Because there's no totality to the body, no synthetic unity. There are pieces, zones, fragments. There's one bit after another, a stomach, an eyelash, a thumb-nail, a shoulder, a breast, a nose, an upper intestine, a choledoch, a pancreas: anatomy is endless, until eventually running into an exhaustive enumeration of cells. But this doesn't yield a totality [...] The pieces, the cells, change as the calculation enumerates in vain. (2008: 157)

Because there is no totality, no unity of a body, Nancy rejects the idea of "one's own body" (corps propre, in the phenomenological tradition). He claims that the body I refer to as "my body" or "I" is always part of a constellation of other bodies, animated or unanimated ones. Moreover, the body to which I say "I" and "my" consists largely of Fremdkörper based on technological developments such as clothing, tools, props, devices, aids, medication, treatments, and so on (reference author). As he so succinctly described in his essay "The Intruder" (2008: 161-170) that deals with his heart transplantation., what we normally call our own "I" or our "own body" has always been determined by something else, something strange or other.

Nancy's ontology of the body thus also implies an "un-doing of bodily identity" (Perpich 2005). According to Perpich, such a deconstruction can help to account for "borderline bodies," such as intersexed bodies; surrogate bodies; pregnant bodies; and punk bodies covered with tattoos, piercings, and scars (2005: 87). We can also add here the female fat body. Gay touches in various ways on the issue of identity instability and the undoing of identity. For example, she writes about the volatility of her own gender identity, which is directly related to her fat embodiment. Others often regard her as a man because she has such a large body, thus denying her gender identity: "I am large, but I am a woman. I deserve to be seen as such" (2017: 233). However, on the same page, she writes that she used to like to come across as somewhat masculine and tough, and that she, therefore, choose to wear men's clothes: "I inhabited a butch identity because it felt safe. It afforded me a semblance of control over my body and how my body was perceived" (2017: 233). Later on, she shed that identity because she felt that she was only playing a role (2017: 234). She also describes taking a tattoo as a practice through which she can partially disintegrate and overwrite her identity as a black fat woman. Gay describes how she enjoys the touch, the submission, and the pain of having a tattoo done. This makes her feel connected to her body in a way that is rarely allowed to her (2017: 169). But a tattoo is, of course, also an identity marker; it says something about how someone thinks his or her body should be. Gay says:

With my tattoos, I get to say, these are choices I make for my body, with fullthroated consent. This is how I mark myself. This is how I take my body back. (2017: 168)

As Langellier has argued, the practice of tattooing one's body can be considered as replacing a text on a palimpsest (2001: 145). If indeed, we consider the body as a palimpsest, then it becomes possible to apply new inscriptions to it each time, creating different layers of meaning. 
That Gay's writing problematizes stable identity formation becomes most evident in her ambiguous attitude towards fat acceptance movements. On the one hand, she indicates that these movements do important work that forms "a necessary corrective to our culture's toxic attitude toward women's bodies and fat bodies" (2017: 140). On the other, however, she states that she does not know where she would fit in with communities of fat people. More importantly, she states that a large part of fat acceptance should involve "unconditional self-acceptance" (2017: 139). Gay's memoir, however, is far from being an account of self-acceptance. It is a testimony of a body she usually hates and sometimes tolerates and loves; a testimony of wanting to stay the same on the one hand, but wanting to have a different appearance on the other; a testimony of wanting to lose weight but also wanting to have a protective large body. Here it becomes abundantly clear that for Gay the meaning of fat is not just the effect of the iteration of social norms pertaining to bodies. If that were the case, it would be much easier to identify with "being fat" in a positive way, and perhaps to embrace it as an honorary epithet. Gay keeps saying she is not able to do so. She gives a piercing description of the lived experience of fat embodiment which underlines the difficulty and struggle of embracing a fat body identity. Her text exposes that the marginalization or exclusion of fat bodies is in part also an effect of material mismatches or misfits.

Even though Gay started her book with the statement that her story is not a story of triumph, she ends it on a rather positive note. She describes that by living in her body she has developed greater empathy for others and the reality of their bodies. "My body has forced me to be more mindful of how other bodies, of differing abilities, move through the world" (2017: 272). In the final chapter, she forcefully claims: "I don't want to change who I am" (2017: 277). However, at the same time, she also indicates that she wants to change something: "I no longer need the fortress I built. I need to tear down some of the walls, and I need to tear down those walls for me and me alone, no matter what good may come of that demolition. I think of it as undestroying myself" (2017: 277). She wants to stay the same while disassembling her body-as-fortress-identity. This proposition shows that she considers it possible to release part of her embodied identity. She considers it possible to detach the meaning "fortress" - the fortress that was not only a protective shield but that also formed a cage in which she was trapped (2017: 15)-from the material signifier fat. For Gay, the condition of the possibility for mobilizing this meaning of fat is not necessarily weight loss or being included in a fat acceptance community, but rather feeling more comfortable in her own body (2017: 277).

\section{Conclusion: Corpus of Corpulence}

What Gay shows in her book is that this "being comfortable" is neither an issue of her biological body's physical size nor exclusively an issue of whether or not her body meets social norms. The experience of being (un)comfortable takes place and takes shape within a constellation that can be represented, in a Nancian style, employing the following corpus: 
fat tissue; weight; stamina; sweat; chairs; seat belts; clothes; side-walks; walking-talking; tattoo; make-up; fortress; legs that rub against each other; swimming pool; being hungry; food; cigarettes; diets; thinspiration; television programs; medical advice; physicians; Haitian-American family; rural America; racism; sexism; rape; hate; feminism; fat acceptance movements; being online; writing.

This enumeration forms the corpus - the collection without unity-of Gay's non-unified fat identity. This corpus comprises various manifestations of agential matter, ranging from fat tissue that presses on other parts of the body to how the public space is materially arranged (as substantiation of social norms). Corpus stands for the relation (the extra of the partes extra partes) between all these different material parts. It is a collection, but one that is open for constant change.

As Colls has argued, a materialist account of fat does not necessarily provide a more "positive account" of fat bodies (2007: 358). The same counts for Gay's corpus of corpulence. What I have sought to establish in this paper is that Gay's corpus sets into motion the "lipoliterate" interpretation of fat embodiment without uncritically embracing the ideals of fat acceptance movements. She seems to suggest that the idea of acceptance remains idle as long as one does not feel comfortable. The matter of fat, as we have seen, can lead to discomfort when heaviness leads to an inflated experience of self which hampers the experience of being touched, or when material mismatches between your body and your environment make you feel that you do not fit into this world. However, the matter of fat can also cause comfort when it materializes in the experience of protection and security. Instead of reflecting a struggle with weight loss and weight gain, Gay's book is an account of how to find a balance between the discomfort of heaviness and reduced space and the comfort of security and protection.

In her final paragraph, Gay is very explicit about the role of writing in the process of giving voice to her body. As a professional writer, she has been able to narrate the story of her body, dismantling cast-iron prejudices and beliefs about fat while exposing the vulnerability of her own body. As she makes clear, it is not a story about being fat in general, but an ongoing story about one singular fat body. Nancy has argued that if instead of writing about bodies, we want to respond "to the ongoing protest of bodies in-against—writing," we need some kind of "fragmentation of writing" (2008: 21). Even though Gay's writing style is not fragmentary in the sense of incomplete phrases or paragraphs, her eightyeight short chapters create a space for understanding that the matter of a body can be experienced in different-and sometimes even contradictory-ways. They reflect the precariousness of a fat body's materialization.

Acknowledgements I would like to thank Annemie Halsema and Joni Puranen for their constructive comments on this paper. Colleagues in the Culture Studies department at Tilburg University have provided me with valuable feedback on the initial ideas of this paper during an animated (online) PEERSmeeting Spring 2020. 
Funding This research is funded by a VICI grant from the Dutch Research Council (NWO), Grant Number: $277-20.008 / 2737$.

\section{Declarations}

Conflict of interest Jenny Slatman declares that she has no conflict of interest.

Open Access This article is licensed under a Creative Commons Attribution 4.0 International License, which permits use, sharing, adaptation, distribution and reproduction in any medium or format, as long as you give appropriate credit to the original author(s) and the source, provide a link to the Creative Commons licence, and indicate if changes were made. The images or other third party material in this article are included in the article's Creative Commons licence, unless indicated otherwise in a credit line to the material. If material is not included in the article's Creative Commons licence and your intended use is not permitted by statutory regulation or exceeds the permitted use, you will need to obtain permission directly from the copyright holder. To view a copy of this licence, visit http://creativecommons.org/licen ses/by/4.0/.

\section{References}

Barad, K. (2003). Posthumanist performativity: Toward an understanding of how matter comes to matter. Signs, 28(3), 801-831.

Braidotti, R. (2002). Metamorphoses: Towards a materialist theory of becoming. Polity Press.

Butler, J. (1993). Bodies that matter. On the discursive limits of "sex." Routledge.

Colls, R. (2007). Materialising bodily matter: Intra-action and the embodiment of 'fat'. Geoforum, 38(2), 353-365.

Cooper, L., Ells, L., Ryan, C., \& Martin, D. (2018). Perceptions of adults with overweight/obesity and chronic musculoskeletal pain: An interpretative phenomenological analysis. Journal of Clinical Nursing, 27(5-6), e776-e786.

Forth, C. E. (2013). The qualities of fat: Bodies, history, and materiality. Journal of Material Culture, 18(2), 135-154.

Fox, N. J., Bissell, P., Peacock, M., \& Blackburn, J. (2018). The micropolitics of obesity: Materialism, markets and food sovereignty. Sociology, 52(1), 111-127.

Gaesser, G. (2009). Is "Permanent Weight Loss" an Oxymoron? The statistics on weight loss and the national weight control registry. In E. Rothblum \& S. Solovay (Eds.), The fat studies reader (pp. 37-41). New York University Press.

Garland-Thomson, R. (2011). Misfits: A feminist materialist disability concept. Hypatia, 26(3), 591-609.

Gay, R. (2017). Hunger. A memoir of (my) body. Corsair.

Graham, M. (2005). Chaos. In D. Kulick \& A. Meneley (Eds.), Fat: The anthropology of an obsession (pp. 169-184). Jeremy P. Tarcher/Penguin.

Grosz, E. A. (1994). Volatile bodies: Toward a corporeal feminism. Indiana University Press.

Groven, K. S., Råheim, M., \& Engelsrud, G. (2013). Dis-appearance and dys-appearance anew: Living with excess skin and intestinal changes following weight loss surgery. Medicine, Health Care and Philosophy, 16(3), 507-523.

Harding, K., \& Kirby, M. (2009). Lessons from the fat-o-sphere: Quit dieting and declare a truce with your body. Perigree.

Jakešová, M. (2020). Mass of bodies, body as a mass: The other of the Other in Jean-Luc Nancy. Research in Phenomenology, 50(1), 17-30.

James, I. (2006). The fragmentary demand: An introduction to the philosophy of Jean-Luc Nancy. Stanford University Press.

Kolata, G. B. (2007). Rethinking thin: The new science of weight loss-and the myths and realities of dieting. Farrar. 
Langellier, K. M. (2001). "You're marked:” Breast cancer, tattoo and the narrative performance of identity. In J. Brockmeier \& D. Carbaugh (Eds.), Narrative and identity: Studies in autobiography, self, and culture (pp. 145-184). John Benjamins Publishing Company.

LeBesco, K. (2004). Revolting Bodies?: The struggle to redefine fat identity. University of Massachusetts Press.

Mollow, A. (2015). Disability studies gets fat. Hypatia, 30(1), 199-216.

Morin, M.-E. (2012). Jean-Luc Nancy. Polity Press.

Morin, M.-E. (2016). Corps propre or corpus corporum: Unity and dislocation in the theories of embodiment of Merleau-Ponty and Jean-Luc Nancy. Chiasmi International, 18, 333-351.

Murray, S. (2008). The "fat" female body. Palgrave Macmillan.

Nancy, J.-L. (1996). Being singular plural. Stanford University Press.

Nancy, J.-L. (1997). The gravity of thought. Humanity Books.

Nancy, J.-L. (2008). Corpus. Fordham University Press.

Natvik, E., Groven, K. S., Råheim, M., Gjengedal, E., \& Gallagher, S. (2019). Space perception, movement, and insight: Attuning to the space of everyday life after major weight loss. Physiotherapy Theory and Practice, 35(2), 101-108.

Noll, J. G., Zeller, M. H., Trickett, P. K., \& Putnam, F. W. (2007). Obesity risk for female victims of childhood sexual abuse: A prospective study. Pediatrics, 120(1), 61-67.

Norman, M. E., \& Moola, F. J. (2019). The weight of (the) matter: A new material feminist account of thin and fat oppressions. Health, 23(5), 497-515.

Oliver, M. (1996). Understanding disability: From theory to practice. Macmillan.

Perpich, D. (2005). Corpus meum: Disintegrating bodies and the ideal of integrity. Hypatia, 20(3), 75-91.

Rice, C. (2015). Rethinking fat: From bio-to body-becoming pedagogies. Cultural Studies Critical Methodologies, 15(5), 387-397.

Royce, T. (2009). The shape of abuse. Fat oppression as a form of violence against women. In E. Rothblum \& S. Solovay (Eds.), The fat studies reader (pp. 151-157). New York University Press.

Shakespeare, T. (2013). Disability rights and wrongs revisited. Routledge.

Sneed, M. M. (2012). Blogging in the fatosphere: A qualitative study of perceptions of personal risks and benefits for women who blog about weight, weight loss, and dieting issues. Electronic Theses and Dissertations. Paper 1495: https://dc.etsu.edu/etd/.

Vartanian, L. R., Pinkus, R. T., \& Smyth, J. M. (2014). The phenomenology of weight stigma in everyday life. Journal of Contextual Behavioral Science, 3(3), 196-202.

Warin, M. (2015). Material feminism, obesity science and the limits of discursive critique. Body and Society, 21(4), 48-76.

Windram-Geddes, M. (2013). Fearing fatness and feeling fat: Encountering affective spaces of physical activity. Emotion, Space and Society, 9, 42-49.

Zahavi, D. (2020). The practice of phenomenology: The case of Max van Manen. Nursing Philosophy, 21(2), e12276.

Publisher's Note Springer Nature remains neutral with regard to jurisdictional claims in published maps and institutional affiliations. 